\title{
Single-Layered Paper-Based Microfluidic Devices Made by Paint-Spraying Technique with Great Barrier Resistance for Colorimetric Assays
}

\author{
Beixi Nie, ${ }^{\#, a}$ Shaoyu Zhao, ${ }^{\#, a}$ Muhan Deng, ${ }^{\#, a}$ Peng Yu, ${ }^{\circ *, a}$ Yi Yang, ${ }^{a}$ Weixin Lei ${ }^{a}$ and Lu Yin ${ }^{a}$ \\ ${ }^{a}$ School of Materials Science and Engineering, Xiangtan University, 411105 Xiangtan, China
}

\begin{abstract}
The single-layered paint-spraying paper based microfluidic devices (sp- $\mu$ PADs) have been for the first time integrated with the colorimetric assay. The polymethyl methacrylate (PMMA) board was applied as the mask instead of the iron mask, reducing the power requirement of the cutting machine. The paint was sprayed into the paper, which blocked the pores of the paper and constructed the hydrophobic barrier on the paper. The paint barrier was highly resistant to the various kind of chemicals and the minimum channel dimensions was $1.4 \mathrm{~mm}$. By using the PMMA masks with different designs, the sp- $\mu$ PADs with different designs have been fabricated and successfully applied to the single analyte assay of iron or bovine serum albumin (BSA) and the simultaneous assay of copper and nickel. Moreover, the feasibility of the multiplexed assay of eight analytes was also demonstrated. The analytical performances indicated that the fabricated sp- $\mu$ PADs offered a promising platform in the colorimetric assays of either single or multiple analytes.
\end{abstract}

Keywords: microfluidics, paper-based devices, paint spraying, colorimetry

\section{Introduction}

Microfluidic paper-based devices ( $\mu$ PADs) have become an alternative point-of-care (POC) analytical tool since the work reported by Whitesides and co-workers in 2007. ${ }^{1}$ The $\mu$ PADs possess the advantages of simplicity, portability, miniaturization, in-field capability and low-cost with a comparison to the traditional measurement methods. ${ }^{2}$ In recent years, $\mu$ PADs have been integrated with various kind of analytical techniques, such as mass spectrometry (MS),, 3 electrochemistry, ${ }^{5,6}$ surface plasmon resonance (SPR), ${ }^{7,8}$ colorimety, ${ }^{9-11}$ fluorometry, ${ }^{12-14}$ electrophoresis, ${ }^{15}$ chromatography, ${ }^{16}$ and chemiluminescence. ${ }^{17,18}$ Among these techniques, the colorimetry integrated with $\mu$ PADs was most attractive, in which color or light intensity variations are monitored by a mobile phone camera or a color image scanner, and analyzed by an open source image processing program.${ }^{19}$ The colorimetric $\mu$ PADs have been used for rapid qualitative and quantitative analysis in various fields such as biochemical analysis, food safety, environmental monitoring, and point-of-care clinical diagnostics. ${ }^{20-24}$

One of the major challenges in the fabrication of $\mu \mathrm{PADs}$ is to pattern the hydrophilic paper with hydrophobic materials to define a reaction zone for the analyte measurement. ${ }^{25}$

*e-mail: yupeng@xtu.edu.cn

\#These authors contributed equally to the paper.
Up to now, many techniques have been developed for the fabrication of $\mu$ PADs. The photolithography technique, while expensive, produces devices with high resolution. ${ }^{26}$ This method requires the usage of the clean room facilities including UV light sources, expensive photoresists, and oxygen plasma. Polydimethylsiloxane (PDMS) plotting, ${ }^{27}$ screen-printing, ${ }^{28}$ wax-printing, ${ }^{29}$ ink-jet printing ${ }^{30}$ and laser cutting ${ }^{31}$ need the specialized instruments and the accompanying consumables. Other groups ${ }^{32-34}$ have developed some instrumental-free techniques including stamping and drawing with permanent marker pen or eyeliner pencil. However, up-scaling such a production technique has been proven to be difficult. Therefore, it is highly desirable to develop a new low-cost approach, allowing for the rapid prototyping and the large scale manufacture of $\mu$ PADs.

Spraying technology has become a new prototyping process for the $\mu$ PADs manufacture emerging in recent years. Compared with the classic wax-printing technique, the spraying technology avoided the printing process, representing a major breakthrough in the $\mu$ PADs manufacture ${ }^{35}$ Coltro and co-workers ${ }^{36}$ described a glue-spraying technique for fabricating the $\mu \mathrm{PADs}$ and the hydrophobic barriers were created by the available scholar glue. In order to produce high resistance barrier, the paper coated with glue was dried at $130{ }^{\circ} \mathrm{C}$ for $60 \mathrm{~min}$ and then exposed under a halogen spotlight for $30 \mathrm{~min}$. 
This tedious heating step significantly increased the time for the $\mu$ PADs fabrication. Chailapakul and co-workers ${ }^{37}$ proposed a spraying method with paint for the $\mu \mathrm{PADs}$ fabrication. The paint is water resistant and good adhesive to various kinds of materials, and does not require the complex drying step. ${ }^{38}$ The patterned iron mask was used to confine the barrier, proposing a higher requirement for cutting machines and undoubtedly increasing the fabrication cost. Additionally, the paint spraying $\mu$ PADs developed by Chailapakul and co-workers ${ }^{37}$ was applied for the electrochemical detection of $\mathrm{Ni}^{\mathrm{II}}$. So far, no work has been reported on the colorimetric detection of one or more analytes with the paint spraying $\mu$ PADs.

In this work, the single-layered paint-spraying $\mu \mathrm{PADs}$ (sp- $\mu$ PADs) were integrated with the colorimetric method for the assays of one or more analytes. The patterned polymethyl methacrylate (PMMA) boards were used as the mask for the fabrication of sp- $\mu$ PADs, which is cheaper than the iron mask. Spray paint was utilized to manufacture the two-dimensional channels in the filter paper. At first, the filter paper was masked with the patterned PMMA boards and then sprayed with the paint. After that, the painted filter paper was dried in an oven. Both the simple and complex fluidic patterns were successfully fabricated by the paint spraying prototyping process. The barrier resistance and the smallest channel size were investigated. Moreover, the validation of the sp- $\mu$ PADs was demonstrated by detecting one or more analytes based on the color intensity analysis or the distance analysis.

\section{Experimental}

\section{Chemicals and equipments}

Whatman filter paper No. 1 was used for sp- $\mu$ PADs fabrication, which was bought from Whatman International Ltd. (Maidstone, England). Spray paint with a volume of $400 \mathrm{~mL}$ per can (blue color or yellow color) was purchased from the local automotive products shop for constructing the channels. The design of the mask was drawn by the software of ZWCAD. ${ }^{39}$ The polymethyl methacrylate (PMMA) board (1 mm in thickness) was cut according to the design by a local laser cutting shop. The binder clips with a width of $19 \mathrm{~mm}$ were applied to fix the position of the PMMA boards on the filter paper. Bovine serum albumin (BSA), sodium lactate, tetrabromophenol blue (TBPB), chitosan with a viscosity of $400 \mathrm{mPa} \mathrm{s}$, 3,3',5,5' -tetramethylbenzidine (TMB), the universal indicator, glucose oxidase (GOx) from Aspergillus niger $\left(>180 \mathrm{U} \mathrm{mg}^{-1}\right.$ ) and peroxidase from horseradish (HRP, $>200$ units $\mathrm{mg}^{-1}$ ) were provided by Aladdin-Reagent
Company (Shanghai, China). Lactate oxidase (LOx) from Aerococcus viridans was bought from Sigma-Aldrich (Shanghai, China). $\mathrm{Fe}\left(\mathrm{NO}_{3}\right)_{3} \cdot 9 \mathrm{H}_{2} \mathrm{O}, 1,10$-phenanthroline monohydrate (phen), ascorbic acid, glucose, potassium thiocyanate, sodium nitrite, citric acid, ethanol, acetic acid, sulfanilamide, $N$-(1-naphthyl) ethylenediamine dihydrochloride (NED), ethylenediaminetetraacetic acid disodium salt (EDTA), sodium diethyldithiocarbamate (DDTC), dimethylglyoxime, tris base, cupric nitrate, nickel nitrate, and other chemicals were purchased from Sinopharm Chemical Reagent Co., Ltd. (Shanghai, China). The deionized water was prepared by a Milli-Q system (Bedford, USA). The pictures of the sp- $\mu$ PADs were obtained by a cellular phone (Huawei Nova, Huawei Technologies Co., Ltd, Shenzhen, China) in a photography box with a size of $40 \times 40 \times 40 \mathrm{~cm}$. The photography box was bought from Shijiazhuang Ruying Film and Television Equipment Sales Co., Ltd. in Shijiazhuang, China and equipped with 84 LED light beads inside. When taking pictures, the cell phone was placed on the photo window at the top of the photography box, and the vertical distance from the prepared $\mu$ PADs was $8 \mathrm{~cm}$. The color intensity in the different color channels (i.e., red (R), green (G) and blue (B) channels) were measured by the ImageJ software. ${ }^{40}$ The purified drinking water produced by China Resources C'estbon Beverage Co., Ltd. in Shenzhen, China was employed as the complex sample for the recovery experiment.

\section{sp- $\mu$ PADs fabricated using a two-step paint spraying prototyping process}

The schematic representation of the two-step paint spraying prototyping process for fabricating the device for the microzone assay was presented in Figure 1. One piece of filter paper was put in between two PMMA masks. The whole device was spray-painted for the first time. The filter paper was then taken out and heated at $60^{\circ} \mathrm{C}$ for $10 \mathrm{~min}$. After that, the two patterned acrylic plates were rotated by 90 degrees and the dried filter paper was put in the middle of the two patterned acrylic plates. Then, the whole device was spray-painted for the second time. The filter paper was then taken out and dried again as mentioned above. A photograph of the actual developed $\mu \mathrm{PAD}$ was provided in Figure 1 and the channel's pattern of the sp- $\mu$ PADs can be easily changed by changing the mask with different designs.

\section{The microzone assay of iron}

Iron is a necessary nutrient to maintain the body growth and development. ${ }^{41}$ Iron deficiency or overload could cause a bad influence on human health. ${ }^{42}$ Thus, iron was detected 


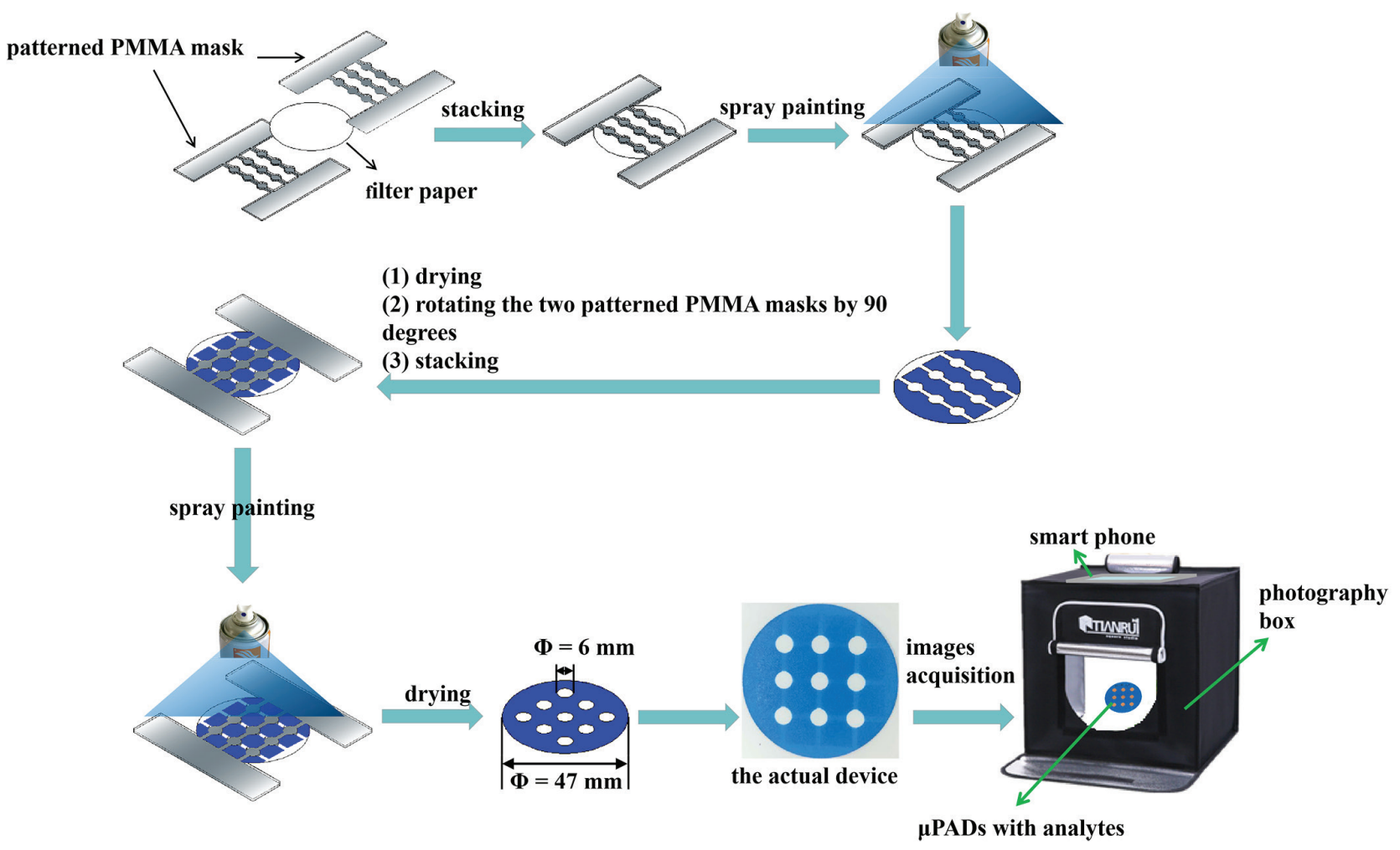

Figure 1. The schematic representation of the two-step paint spraying prototyping process for fabricating the device.

to investigate the application value of the sp- $\mu$ PADs. The reagent for iron assay was prepared by adding $100 \mathrm{mmol} \mathrm{L}^{-1}$ phen, $2 \%(\mathrm{~m} / \mathrm{m})$ ascorbic acid in sodium acetate buffer (20 $\mathrm{mmol} \mathrm{L}^{-1}, \mathrm{pH} 4.6$ ), using 95/5\% (v/v) ethanol/water as the solvent. Then the reagent $(2.5 \mu \mathrm{L})$ was pipetted into the microzone and dried at room temperature (RT) for $6 \mathrm{~min}$. To generate a standard curve, the freshly prepared iron standards $(2.5 \mu \mathrm{L})$ and the blank (ultrapure water) $(2.5 \mu \mathrm{L})$ were added into the microzones of the $\mu \mathrm{PAD}$. The pictures of the sp- $\mu$ PADs were captured by a cell phone and the color intensities in different channels were analyzed by the ImageJ software. ${ }^{40}$

\section{The multiplexed assay of eight analytes}

The eight analytes including BSA, glucose, nitrite, thiocyanate, lactate, $\mathrm{pH}$, copper and nickel were used for the multiplexed assay in this work. For BSA assay, $0.5 \mu \mathrm{L}$ of the reagents including citric acid $\left(250 \mathrm{mmol} \mathrm{L}^{-1}\right)$ and TBPB $\left(3 \mathrm{mmol} \mathrm{L}^{-1}\right)$ in $95 \%$ (v/v) ethanol were pipetted into the outer circular assay zone. ${ }^{43}$ For the assays of glucose and lactate, $0.5 \mu \mathrm{L}$ of chitosan $(0.5 \% \mathrm{~m} / \mathrm{v})$ in acetic acid $(2 \% \mathrm{v} / \mathrm{v})$ was pipetted into the corresponding assay zones. The enzyme solutions in PBS $\left(100 \mathrm{mmol} \mathrm{L}^{-1}, \mathrm{pH}\right.$ 6.0) were composed of GOx $\left(120 \mathrm{U} \mathrm{mL}^{-1}\right)$ and $\mathrm{HRP}\left(30 \mathrm{U} \mathrm{mL}^{-1}\right)$ for glucose assay and LOx $\left(40 \mathrm{U} \mathrm{mL}^{-1}\right)$ and $\mathrm{HRP}\left(300 \mathrm{U} \mathrm{mL}^{-1}\right)$ for lactate assay, respectively. $0.5 \mu \mathrm{L}$ of TMB solution $\left(15 \mathrm{mmol} \mathrm{L}^{-1}\right)$ was then pipetted into the assay zones. ${ }^{44,45}$ For nitrite assay, the Griess reagent was composed of NED $\left(10 \mathrm{mmol} \mathrm{L}^{-1}\right)$, sulfanilamide $\left(50 \mathrm{mmol} \mathrm{L}^{-1}\right)$, and citric acid $\left(330 \mathrm{mmol} \mathrm{L}^{-1}\right) .0 .5 \mu \mathrm{L}$ of the Griess reagent was added into the assay zone. ${ }^{44}$ For thiocyanate assay, $0.5 \mu \mathrm{L}$ of the solution containing $600 \mathrm{mmol} \mathrm{L}^{-1} \mathrm{Fe}^{\mathrm{III}}$ was added into the outer circular assay zone. ${ }^{33}$ For $\mathrm{pH}$ assay, $0.5 \mu \mathrm{L}$ of the universal indicator were pipetted into the outer circular assay zone. ${ }^{46}$ For $\mathrm{Cu}^{\mathrm{II}}$ assay, $0.5 \mu \mathrm{L}$ of the solution containing $150 \mathrm{mmol} \mathrm{L}^{-1}$ EDTA and $5 \mathrm{mmol} \mathrm{L}^{-1}$ DDTC ( $\mathrm{pH}$ 7.6) was pipetted into the outer circular assay zone. ${ }^{47}$ For nickel(II) assay, $0.5 \mu \mathrm{L}$ of the sensing solution composed of dimethylglyoxime $\left(50 \mathrm{mmol} \mathrm{L}^{-1}\right)$ and tris base $\left(50 \mathrm{mmol} \mathrm{L}^{-1}\right)$ in $95 / 5 \%$ ethanol/ $\mathrm{H}_{2} \mathrm{O}$ solvent was pipetted into the outer circular assay zone. ${ }^{48}$ All these reagents were allowed to dry at RT for $10 \mathrm{~min}$. Then, the model mixture containing the eight analytes $(15 \mu \mathrm{L})$ was added to the circular zone in the center. After 10 min of reaction, the photo of the flower-shaped $\mu$ PADs were taken using a smartphone.

\section{Results and Discussion}

\section{Characterization of the fabricated $\mathrm{sp}-\mu \mathrm{PADs}$}

The technical challenge in the sp- $\mu$ PADs fabrication is how to control fluid flow in the channels. ${ }^{49}$ In order to 
achieve this goal, it is critical to construct the clear boundary to distinguish the hydrophilic area and the hydrophobic area. First, the hydrophobic property of the paint barrier was investigated. The water droplet was dropped on the surface of the sp- $\mu$ PADs and the picture was shown in Figure 2A. The contact angle with water was $134^{\circ}$, indicating that the area deposited by paint exhibits hydrophobicity. The reason is that the paint blocked the pores in the filter paper, forming an hydrophobic interface on the surface of the paper. For the fabrication of device, it is critical to make sure that the paint fully penetrates into the filter paper. The fabricated $\mu \mathrm{PAD}$ was cut along the red dotted line and the cross section was observed by an optical microscope. It is clearly shown that the paint fully penetrates into the filter paper in the hydrophobic area and there is a well-defined boundary between the hydrophobic area and the hydrophilic area (Figure 2B). The manufacturing cost of a single device (including the cost of PMMA masks and laser cutting, filter paper, paint) is ca. US\$ 0.17 , manifesting the low cost of the paint spraying method. The channel size was calibrated and the results were presented in Figure 2C. The fabricated device for the channel size calibration possessed 12 radiating channels with the width ranging from 0.1 to $2 \mathrm{~mm}$. It is noted that the smallest channel which was able to be filled in the entire length of the channel with red food dye, was revealed to be $1.4 \mathrm{~mm}$ with a designed width of $1.5 \mathrm{~mm}$.
Investigation of the barrier resistance

The resistance when exposed to the various kinds of chemicals has been demonstrated. The paint with yellow color were used for the fabrication of the distance-based sp- $\mu$ PADs to get a clear barrier view. The sp- $\mu$ PADs used for this experiment included a circular zone for sample introduction with a radius of $4 \mathrm{~mm}$ and a channel with a width of $2 \mathrm{~mm}$, whose size was marked in the Figure 3A. Different solutions $(25 \mu \mathrm{L})$ with food dye was added in the circular zone and the optical micrographs were obtained 20 min later. The micrographs were presented in Figure 3B and indicated that the paint barrier exhibited the high chemical resistance towards the various kinds of chemicals such as acid and alkaline solutions, organic solvents, surfactants, buffer solution and the reducing reagent.

The microzone assay performance for iron

The microzone array consisted of 9 zones arranged into 3 columns and 3 rows. To investigate the capability of the developed device, iron was used as the model analyte. The sp- $\mu$ PADs for iron assay was feasible and the optimized parameter was obtained experimentally. The results shown in Figure S1 (Supplementary Information (SI) section) indicated that the B channel was selected as

(A)



(B)

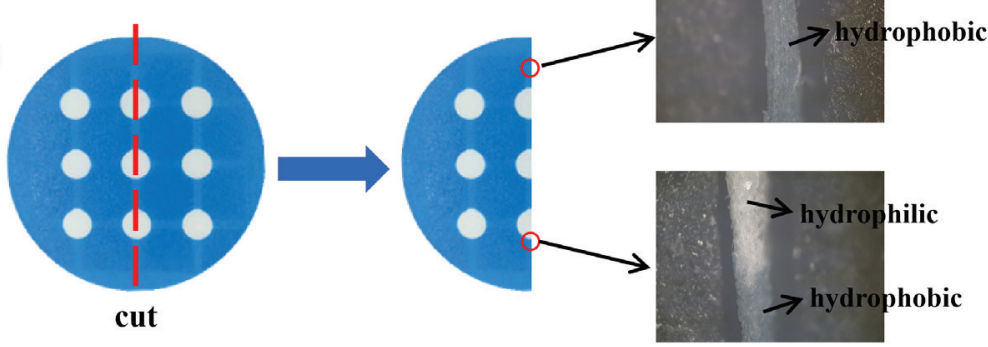

(C)

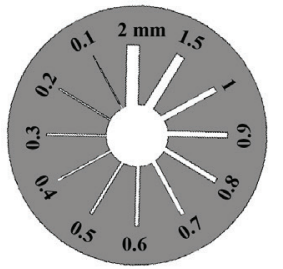

(a)

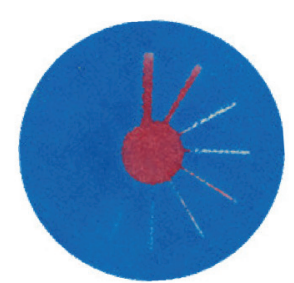

(b)

Figure 2. (A) The picture obtained after the water droplet was dropped on the surface of the sp- $\mu$ PADs. (B) The cross section of the sp- $\mu$ PADs captured under an optical microscope at $225 \times$ magnification. (C) The design of the device for the channel size calibration (a) and the fabricated device treated with the red food dye (b). 
(A)
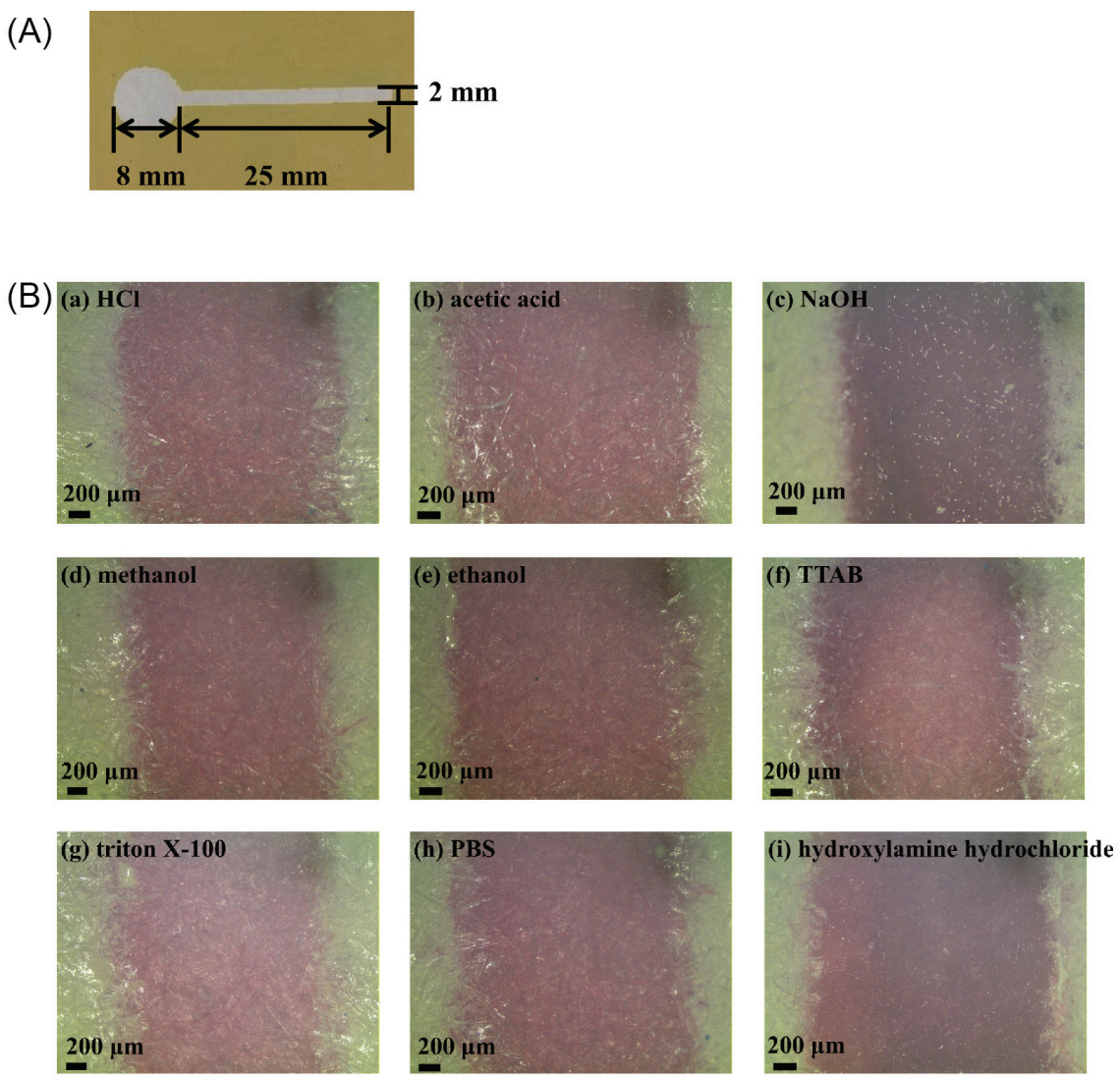

Figure 3. (A) The fabricated distance-based sp- $\mu$ PADs. (B) The optical micrographs of the paint barrier after adding different solutions: (a) 150 mmol $\mathrm{L}^{-1}$ hydrochloric acid, (b) $150 \mathrm{mmol} \mathrm{L}-1$ acetic acid, (c) $150 \mathrm{mmol} \mathrm{L}^{-1}$ sodium hydroxide, (d) $50 \%$ (v/v) methanol, (e) 50\% (v/v) ethanol, (f) 5\% (m/v) tetradecyltrimethylammonium bromide (TTAB), (g) $5 \%(\mathrm{~m} / \mathrm{v})$ triton X-100, (h) phosphate buffer solution (PBS) (100 mmol L-1 $\mathrm{pH}^{7.4)}$, (i) $150 \mathrm{mmol} \mathrm{L}^{-1}$ hydroxylamine hydrochloride.

the analytical signal due to its high sensitivity. The results in Figure S2 (SI section) indicated that $100 \mathrm{mmol} \mathrm{L}^{-1}$ was the optimized concentration of phen for iron assay. Under the optimized conditions, a series of $\mathrm{Fe}^{\mathrm{III}}$ standards were pipetted into the microzones. The assay color intensity was analyzed using ImageJ software. ${ }^{40}$ It is noted from Figure 4a that the color in the assay zone gradually darken with the concentrations of $\mathrm{Fe}^{\mathrm{III}}$ increasing from 0 to $400 \mathrm{mg} \mathrm{L}^{-1}$, resulting in a notable decrease in the blue channel intensity. Figure $4 \mathrm{~b}$ shows that a strong linear calibration plot (blue channel intensity $=-0.7235 \mathrm{C}_{\mathrm{Fe}}+202, \mathrm{R}^{2}=0.9951$ ) was obtained with a linear range from 5 to $150 \mathrm{mg} \mathrm{L}^{-1}$. The limit of detection (LOD) was calculated to be $2.2 \mathrm{mg} \mathrm{L}^{-1}$ by $3 \sigma / \mathrm{S}, \sigma$ is the standard deviation of the signal in nine parallel blank measurements and $\mathrm{S}$ is the slope of the calibration equation. For comparison, some representative chemosensors for iron detection are summarized in Table 1. It is noted that the performance of the sp- $\mu$ PADs in this work were comparable with most of the literature listed in Table 1 . The $\mu$ PADs fabricated by Henry and co-workers ${ }^{54,55}$ presented the lower LOD for iron assay using the same reaction. The possible reason is that the poly(acrylic acid) and polyethylene glycol were added to immobilize the colored product and increase the hydrophilicity in the reservoir, resulting in the better assay performance.

To investigate the anti-interference ability of the fabricated sp- $\mu$ PADs, the selectivity experiment was carried out using several common interferent ions as the interferents $\left(\mathrm{Ca}^{\mathrm{II}}, \mathrm{Co}^{\mathrm{II}}, \mathrm{K}^{\mathrm{I}}, \mathrm{Mg}^{\mathrm{II}}, \mathrm{Na}^{\mathrm{I}}, \mathrm{Ni}^{\mathrm{II}}, \mathrm{Pb}^{\mathrm{II}}, \mathrm{Zn}^{\mathrm{II}}\right)$. Figure S3 (SI section) shows the images and the color values in the B channel of the assay zones with different ions. With a comparison to the blank, $\mathrm{Fe}^{\mathrm{III}}$ solution (100 $\left.\mathrm{mg} \mathrm{L}^{-1}\right)$ produced an orange-red color in the detection zone and resulted in a significant decrease of the color intensity. The other ions (10000 $\left.\mathrm{mg} \mathrm{L}^{-1}\right)$ produced no color with the reagent. The color intensities obtained in the interferents were almost the same as the intensity obtained in the blank, demonstrating the good selectivity of the sp- $\mu$ PADs for $\mathrm{Fe}^{\mathrm{III}}$ detection. The repeatability was investigated by performing the determination of five concentration levels $\left(5,30,50,100,150 \mathrm{mg} \mathrm{L}^{-1}\right)$ with nine replicate measurements using the sp- $\mu$ PADs. For the five concentration levels investigated, the relative standard deviations (RSD) were 4.6, 4.5, 3.6, 3.5 and $4.8 \%$, respectively. The results demonstrated that the developed sp- $\mu$ PADs performed a satisfactory repeatability. 
Table 1. The performance contrast of the different chemosensors for iron detection

\begin{tabular}{|c|c|c|c|c|}
\hline Sensing reagents/materials & Method & Linear range / $\left(\mathrm{mg} \mathrm{L}^{-1}\right)$ & $\mathrm{LOD} /\left(\mathrm{mg} \mathrm{L}^{-1}\right)$ & Reference \\
\hline Compound $2^{\mathrm{a}}$ & fluorescence & & 2.4 & 50 \\
\hline Gold nanoparticles and acidic thiourea mixture & colorimetric & $100-500$ & 50 & 51 \\
\hline Bathophenanthroline $^{b}$ & colorimetric & $3.3-470$ & 3.3 & 48 \\
\hline Bathophenanthroline $^{b}$ & colorimetric & $20-1300$ & 20 & 48 \\
\hline Sensor $5^{c}$ & fluorescence & & 5.2 & 52 \\
\hline Phen & colorimetric & $5-125$ & & 53 \\
\hline Phen & colorimetric & $5-150$ & 2.2 & this work \\
\hline
\end{tabular}

a3-(4-(Dimethylamino)phenyl)-1-(5-methyl-1-(naphthalen-1-yl)-1H-1,2,3-triazol-4-yl)prop-2-en-1-one; b4,7-diphenyl-1-1,10-phenanthroline; c5-ethoxycarbonyl-6-methyl-4-phenyl-2-[(7-chloroquinolin-4-ylamino)butylamino]pyrimidine. LOD: limit of detection; phen: 1,10-phenanthroline monohydrate.
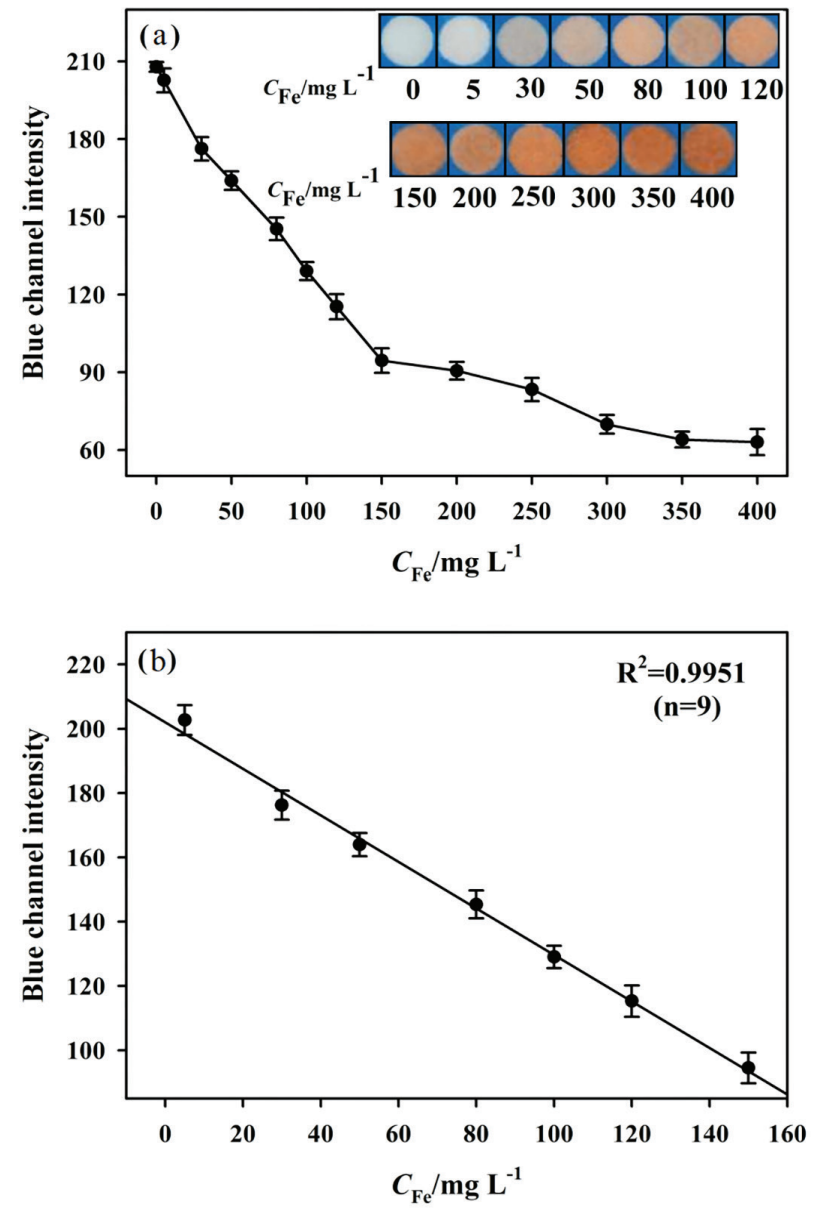

Figure 4. (a) The results for iron assay. Inset: the pictures of the microzones after adding a series of $\mathrm{Fe}^{\mathrm{III}}$ standards. (b) Calibration curve for iron assay.

To study the practicability of the sp- $\mu$ PADs for iron assay, the recovery test was performed using the drinking water as the real world sample. Iron was not detected in the drinking water by our method. The possible reason may be that the concentration of iron in the sample was below the LOD, or there was no iron in the water sample. The water sample was spiked with the standard solutions of $\mathrm{Fe}^{\mathrm{III}}$. The results of applying the assay to the real world sample are listed in Table S1 (SI section). The recoveries of $\mathrm{Fe}^{\mathrm{III}}$ ranged from 94.0 to $108.8 \%$. In addition, all the RSD values of the recovery test were found to be below $4 \%$, showing that the sp- $\mu$ PADs were suitable for iron assay in the real world sample.

The simultaneous assay of copper and nickel

The applicability was also demonstrated by the simultaneous assay of copper and nickel. The assay reagents for the two ions assay were described in the "The multiplexed assay of eight analytes" sub-section. The fabricated device for this experiment was designed with two assay zones on both sides and one sample introduction zone in the center. All the circular zones in the device were designed with a diameter of $6 \mathrm{~mm}$. The size of the channels between the circular zones was $5.4 \mathrm{~mm}$ (length) $\times 2 \mathrm{~mm}$ (width). $1.8 \mu \mathrm{L}$ of the reagents were added in the assay zones on both sides and dried at RT for $10 \mathrm{~min} .20 \mu \mathrm{L}$ of the standard was then added to the circular zone in the center. The photos of the sp- $\mu$ PADs were captured 10 min later and the color intensity was analyzed by the free image processing software. It is noted from Figure 5 that when the concentrations of the analytes increased, the colors in the assay zones became darker, indicating that more complexation between the analyte and reagents was produced. The linear range was 5-9 $\mathrm{mmol} \mathrm{L}^{-1}$ for the copper assay and 1-6 $\mathrm{mmol} \mathrm{L}^{-1}$ for the nickel assay, respectively. The detectable limit was $5 \mathrm{mmol} \mathrm{L}^{-1}$ for the copper assay and $1 \mathrm{mmol} \mathrm{L}^{-1}$ for the nickel assay, respectively. The results demonstrated that the sp- $\mu$ PADs were successfully fabricated and could be extended to the simultaneous assay of two analytes.

The distance-based sp- $\mu$ PADs for the detection of BSA

The distance-based sp- $\mu$ PADs were also prepared by 
(a)

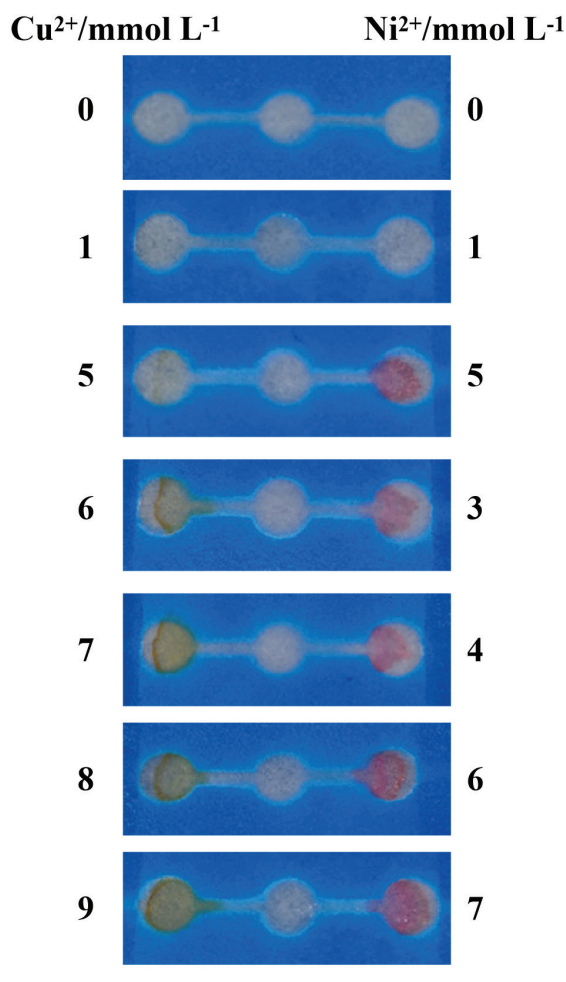

(b)

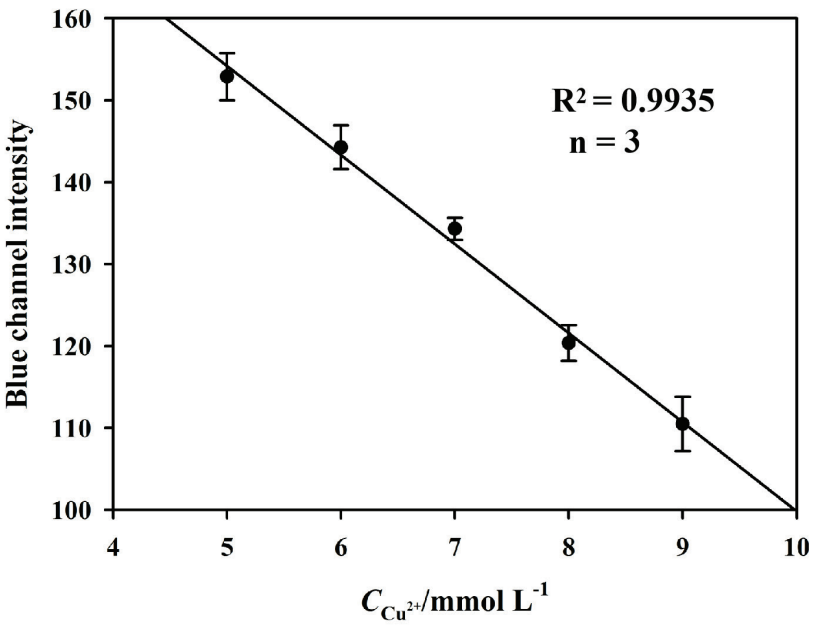

(c)

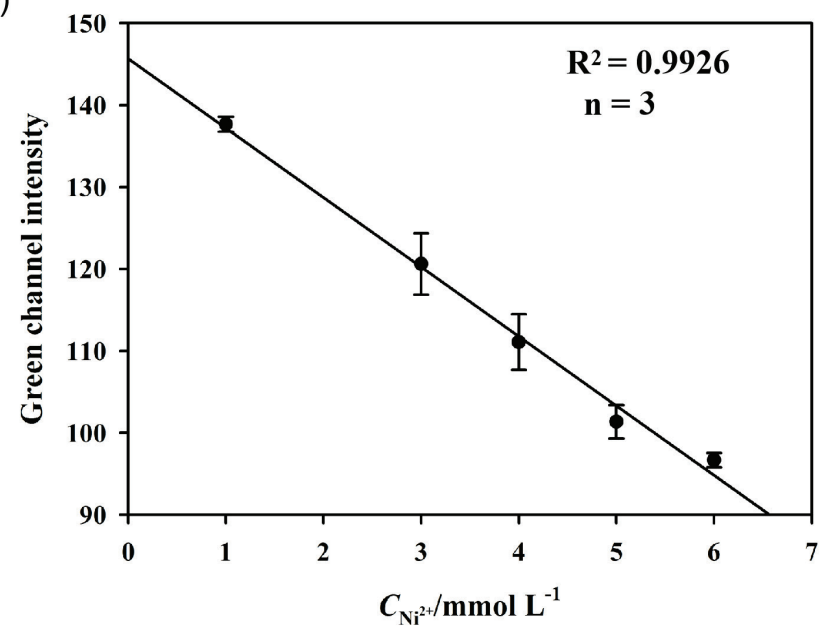

Figure 5. (a) The photos of the sp- $\mu$ PADs for the simultaneous assay of copper and nickel. (b) The calibration curve for copper assay. (c) The calibration curve for nickel assay.

the paint spraying method, consisting of a circular reservoir with a radius of $4 \mathrm{~mm}$ for analyte introduction and a straight channel $(2 \times 25 \mathrm{~mm})$ for the distance measurement. BSA was used as the model analyte to prove the applicability of the distance-based sp- $\mu$ PADs. For the detection of BSA, the reagents including $250 \mathrm{mmol} \mathrm{L}^{-1}$ citric acid and $3 \mathrm{mmol} \mathrm{L}^{-1}$ TBPB were dissolved in $95 \%$ (v/v) ethanol. Then, $3 \mu \mathrm{L}$ of the reagents were pipetted into the straight channel and dried at RT for $10 \mathrm{~min} .25 \mu \mathrm{L}$ of BSA standard was then added to the circular zone. After $5 \mathrm{~min}$ of reaction, the color distance was measured. The photos of the distance-based sp- $\mu$ PADs for BSA assay are presented in the Figure $6 a$. The color of the reagents were yellow but produced a dark blue product that was easily visible after the reaction with BSA. Moreover, when the concentration of BSA increased, the color distance rose higher and higher, indicating a positive correlation between them. It is noted from Figure $6 \mathrm{~b}$ that the linear range for BSA assay was $0.05-1 \mathrm{~g} \mathrm{~L}^{-1}$ and the visual limit of detection was $0.05 \mathrm{~g} \mathrm{~L}^{-1}$. The linearity for the detection of BSA was expressed by the squared correlation coefficient $\left(\mathrm{R}^{2}\right)$, which equaled 0.9881 . Although the first data point $\left(0.05 \mathrm{~g} \mathrm{~L}^{-1}, 1.7250 \mathrm{~mm}\right)$ reduces the correlation between the set of data, it was not removed. The reason is that the urinary albumin excretion (i.e., microalbuminuria) is an important marker for the early-stage renal failure when the levels of urine albumin are between 0.02 and $0.2 \mathrm{~g} \mathrm{~L}^{-1} .{ }^{56}$ Therefore, the distance assay of BSA sacrifices the linearity for the wide dynamic range, which partially overlaps the clinical range of urine albumin. The results demonstrated that the distance-based sp- $\mu$ PADs were successfully fabricated by the paint spraying technique and exhibited a promising prospect for bioassay.

The flower-shaped sp- $\mu$ PADs fabricated by the paintspraying method for the multiplexed assay

More complex design was employed for the device fabrication. The layout of the flower shaped sp- $\mu$ PADs were manufactured with the spraying parameters listed as follows: the channel with a $2.0 \mathrm{~mm}$ width and a $4.5 \mathrm{~mm}$ length, the 
(a)

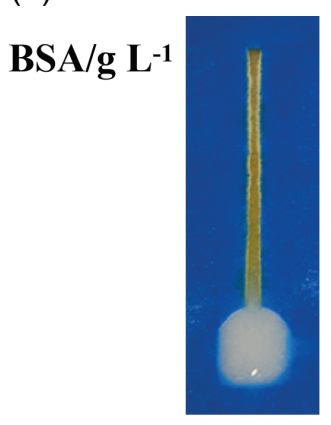

0.05

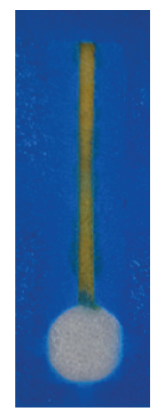

0.1

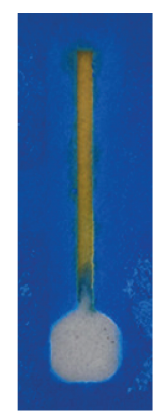

0.3

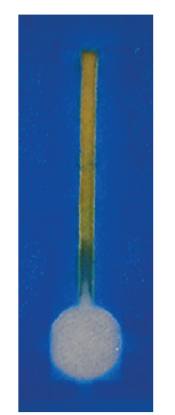

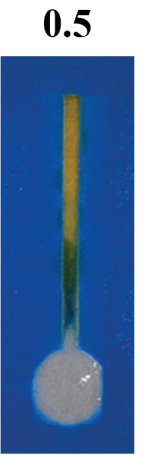

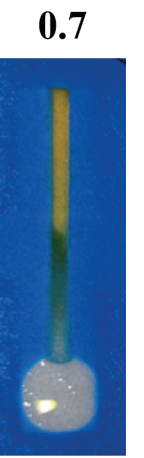

(b)

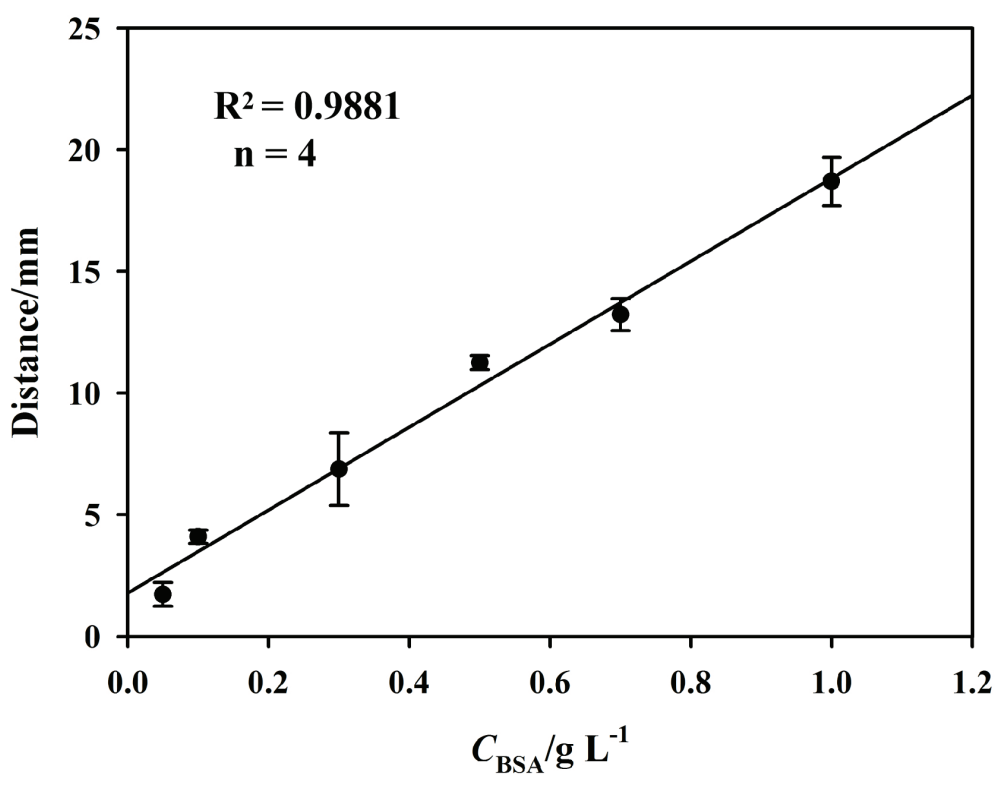

Figure 6. (a) The photos of the fabricated distance-based sp- $\mu$ PADs for BSA assay. (b) The calibration curve for BSA assay.

central analyte introduction reservoir with a diameter of $6.0 \mathrm{~mm}$, the outer circular assay zone with a diameter of $4.0 \mathrm{~mm}$. Figure 7 shows a photograph of the flower-shaped sp- $\mu$ PADs for simultaneously detecting a model mixture containing the eight analytes including BSA $\left(1 \mathrm{~g} \mathrm{~L}^{-1}\right)$, glucose $\left(2 \mathrm{mmol} \mathrm{L}^{-1}\right)$, nitrite $\left(1 \mathrm{mmol} \mathrm{L}^{-1}\right)$, thiocyanate $\left(10 \mathrm{mmol} \mathrm{L}^{-1}\right)$, lactate $\left(20 \mathrm{mmol} \mathrm{L}^{-1}\right), \mathrm{pH}(7), \mathrm{Cu}^{\mathrm{II}}\left(20 \mathrm{mmol} \mathrm{L}^{-1}\right)$ and $\mathrm{Ni}^{\mathrm{II}}$ $\left(20 \mathrm{mmol} \mathrm{L}^{-1}\right)$. These analytes are clinically relevant and commonly measured in biological systems such as urine or saliva, and their values are closely related to the human health. With a comparison to the blank, the eight analytes were successfully detected at the same time. Therefore, certain diseases could be quickly screened by the color changes obtained in the developed flower shaped sp- $\mu$ PADs, providing a great analytical platform for the clinical testing.

\section{Conclusions}

The simple, low-cost sp- $\mu$ PADs have been fabricated by the paint spraying technique with simple or complex designs by changing the patterned PMMA mask. The

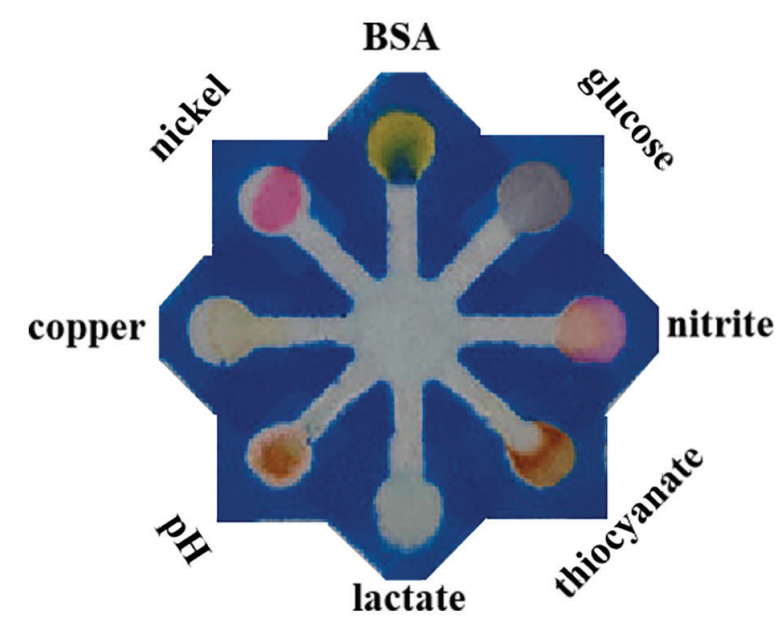

Figure 7. The photograph of the flower-shaped sp- $\mu$ PADs for the multiplexed assay of a model mixture with a volume of $15 \mu \mathrm{L}$ : BSA $\left(1 \mathrm{~g} \mathrm{~L}^{-1}\right)$, glucose $\left(2 \mathrm{mmol} \mathrm{L}^{-1}\right)$, nitrite $\left(1 \mathrm{mmol} \mathrm{L}^{-1}\right)$, thiocyanate $\left(10 \mathrm{mmol} \mathrm{L}^{-1}\right)$, lactate $\left(20 \mathrm{mmol} \mathrm{L}^{-1}\right), \mathrm{pH}(7), \mathrm{Cu}^{\mathrm{II}}\left(20 \mathrm{mmol} \mathrm{L}^{-1}\right)$ and $\mathrm{Ni}^{\mathrm{II}}$ $\left(20 \mathrm{mmol} \mathrm{L}^{-1}\right)$.

applicability of the sp- $\mu$ PADs was proved by implementing colorimetric detections of one or more analytes. The microzone assay performance for iron exhibited a LOD of 
$2.2 \mathrm{mg} \mathrm{L}^{-1}$ and a linear range of 5-150 $\mathrm{mg} \mathrm{L}^{-1}$. The detectable limits for the simultaneous assay of copper and nickel were $5 \mathrm{mmol} \mathrm{L}^{-1}$ for copper assay and $1 \mathrm{mmol} \mathrm{L}^{-1}$ for nickel assay, respectively. The distance-based sp- $\mu$ PADs were successfully fabricated and applied for the detection of BSA with a visual limit of detection of $0.05 \mathrm{~g} \mathrm{~L}^{-1}$. Furthermore, the possible application of the flower-shaped sp- $\mu$ PADs were demonstrated by the multiplexed assay of eight analytes. Accordingly, the sp- $\mu$ PADs offered a promising prospect on detecting single analyte or multiple analytes, showing the potential applications in environmental analysis and bioassays.

\section{Supplementary Information}

Supplementary information is available free of charge at http://jbcs.sbq.org.br as PDF file.

\section{Acknowledgments}

The authors are grateful to the financial support from the Student's Platform for Innovation and Entrepreneurship Training Program (grant number S201910530018) and the Natural Science Foundation of Hunan Province (grant number 2018JJ3500). We are also grateful to Saichon Sumantukul and Matthew Kremer from Oregon State University for project review.

\section{Author Contributions}

B. N., S. Z. and M. D. carried out the experiments and their contributions to the paper were equal. P. Y. designed the $\mu$ PADs, searched the references, and wrote the manuscript. Y. Y. collected the pictures of devices under the optical microscope and contributed to the manuscript edition. W. L. and L. Y. interpreted the data and edited the manuscript.

\section{References}

1. Martinez, A. W.; Phillips, S. T.; Butte, M. J.; Whitesides, G. M.; Angew. Chem., Int. Ed. 2007, 46, 1318.

2. Channon, R. B.; Nguyen, M. P.; Scorzelli, A. G.; Henry, E. M.; Volckens, J.; Dandy, D. S.; Henry, C. S.; Lab Chip 2018, 18, 793.

3. Jiang, Y.; Wang, P. C.; Locascio, L. E.; Lee, C. S.; Anal. Chem. 2001, 73, 2048.

4. Lee, J.; Soper, S. A.; Murray, K. K.; J. Mass Spectrom. 2009, $44,579$.

5. Nie, Z.; Nijhuis, C. A.; Gong, J.; Chen, X.; Kumachev, A.; Martinez, A. W.; Narovlyansky, M.; Whitesides, G. M.; Lab Chip 2010, 10, 477.
6. Sun, X.; Wang, H.; Jian, Y.; Lan, F.; Zhang, L.; Liu, H.; Ge, S.; Yu, J.; Biosens. Bioelectron. 2018, 105, 218.

7. Hassani, A.; Skorobogatiy, M.; Opt. Express 2006, 14, 11616.

8. Malic, L.; Veres, T.; Tabrizian, M.; Biosens. Bioelectron. 2009, 24, 2218.

9. Wang, L.; Musile, G.; McCord, B. R.; Electrophoresis 2018, 39,470 .

10. Ellerbee, A. K.; Phillips, S. T.; Siegel, A. C.; Mirica, K. A.; Martinez, A. W.; Striehl, P.; Jain, N.; Prentiss, M.; Whitesides, G. M.; Anal. Chem. 2009, 81, 8447.

11. Li, B.; Fu, L.; Zhang, W.; Feng, W.; Chen, L.; Electrophoresis 2014, 35, 1152.

12. Fiedoruk-Pogrebniak, M.; Granica, M.; Koncki, R.; Talanta 2018, 178, 31 .

13. Weng, X.; Neethirajan, S.; Microchim. Acta 2017, 184, 4545.

14. Qi, J.; Li, B.; Wang, X.; Fu, L.; Luo, L.; Chen, L.; Anal. Chem. 2018, 90, 11827.

15. Coltro, W. K. T.; de Jesus, D. P.; da Silva, J. A. F.; do Lago, C. L.; Carrilho, E.; Electrophoresis 2010, 31, 2487.

16. Lisowski, P.; Zarzycki, P. K.; Chromatographia 2013, 76, 1201.

17. Caputo, D.; de Cesare, G.; Dolci, L. S.; Mirasoli, M.; Nascetti, A.; Roda, A.; Scipinotti, R.; IEEE Sens. J. 2013, 13, 2595.

18. Kamruzzaman, M.; Alam, A. M.; Kim, K. M.; Lee, S. H.; Kim, Y. H.; Kabir, A. H.; Kim, G. M.; Dang, T. D.; Biomed. Microdevices 2013, 15, 195.

19. Koesdjojo, M. T.; Pengpumkiat, S.; Wu, Y.; Boonloed, A.; Huynh, D.; Remcho, T. P.; Remcho, V. T.; J. Chem. Educ. 2015, 92, 737.

20. Rossini, E. L.; Milani, M. I.; Carrilho, E.; Pezza, L.; Pezza, H. R.; Anal. Chim. Acta 2018, 997, 16.

21. Chabaud, K. R.; Thomas, J. L.; Torres, M. N.; Oliveira, S.; McCord, B. R.; Forensic Chem. 2018, 9, 35.

22. Taghizadeh-Behbahani, M.; Hemmateenejad, B.; Shamsipur, M.; Chem. Pap. 2018, 72, 1239.

23. Liu, C.; Gomez, F. A.; Miao, Y.; Cui, P.; Lee, W.; Talanta 2019 , 194, 171.

24. da Silva, G. O.; de Araujo, W. R.; Paixão, T. R.; Talanta 2018 , 176, 674.

25. Cao, R.; Zhang, X.; Tan, W.; Shen, W.; Cellulose 2018, 25, 583.

26. Asano, H.; Shiraishi, Y.; Anal. Chim. Acta 2015, 883, 55.

27. Abdollahi-Aghdam, A.; Majidi, M. R.; Omidi, Y.; BioImpacts 2018, 8, 237.

28. Puneeth, S. B.; Goel, S.; IEEE Trans. Electron Devices 2019 , 66, 3196.

29. Chiang, C. K.; Kurniawan, A.; Kao, C. Y.; Wang, M. J.; Talanta 2019, 194, 837.

30. Zhang, H.; Smith, E.; Zhang, W.; Zhou, A.; Biomed. Microdevices 2019, 21, 48.

31. Casto, L. D.; Schuster, J. A.; Neice, C. D.; Baker, C. A.; Anal. Methods 2018, 10, 3616. 
32. Cardoso, T. M.; Garcia, P. T.; Coltro, W. K.; Anal. Methods 2015, 7, 7311.

33. Pena-Pereira, F.; Lavilla, I.; Bendicho, C.; Talanta 2016, 147, 390.

34. Atabakhsh, S.; Ashtiani, S. J.; Microfluid. Nanofluid. 2019, 23, 69.

35. Al-Qadiri, H. M.; Ovissipour, M.; Al-Alami, N.; Govindan, B. N.; Shiroodi, S. G.; Rasco, B.; J. Food Sci. 2016, 81, M1177.

36. Cardoso, T. M. G.; de Souza, F. R.; Garcia, P. T.; Rabelo, D.; Henry, C. S.; Coltro, W. K. T.; Anal. Chim. Acta 2017, 974, 63.

37. Nurak, T.; Praphairaksit, N.; Chailapakul, O.; Talanta 2013, 114, 291.

38. Hu, R. G.; Zhang, S.; Bu, J. F.; Lin, C. J.; Song, G. L.; Prog. Org. Coat. 2012, 73, 129.

39. ZWCAD, v.18.0.55.0; Guangzhou Zhongwang Longteng Software Co., Ltd., China, 2018.

40. ImageJ, v.1.50b; National Institutes of Health, USA, 2017.

41. Gammella, E.; Recalcati, S.; Rybinska, I.; Buratti, P.; Cairo, G.; Oxid. Med. Cell. Longevity 2015, 2015, 230182.

42. Kontoghiorghe, C. N.; Kontoghiorghes, G. J.; World J. Methodol. 2016, 6, 1.

43. Garcia, P. T.; Cardoso, T. M. G.; Garcia, C. D.; Carrilho, E.; Coltro, W. K. T.; RSC Adv. 2014, 4, 37637.

44. Yu, P.; Deng, M.; Yang, Y.; Sensors 2019, 19, 4082.

45. Dungchai, W.; Chailapakul, O.; Henry, C. S.; Anal. Chim. Acta 2010, 674, 227.
46. Koh, A.; Kang, D.; Xue, Y.; Lee, S.; Pielak, R. M.; Kim, J.; Hwang, T.; Min, S.; Banks, A.; Bastien, P.; Manco, M. C.; Wang, L.; Ammann, K. R.; Jang, K. I.; Won, P.; Han, S.; Ghaffari, R.; Paik, U.; Slepian, M. J.; Balooch, G.; Huang, Y.; Rogers, J. A.; Sci. Transl. Med. 2016, 8, 366ra165.

47. Xie, G. L.; Yu, H.; Deng, M. H.; Zhao, X. L.; Yu, P.; Chem. Pap. 2019, 73, 1509.

48. Cate, D. M.; Noblitt, S. D.; Volckens, J.; Henry, C. S.; Lab Chip 2015, 15, 2808.

49. Lim, W. Y.; Goh, B. T.; Khor, S. M.; J. Chromatogr. B 2017, 1060, 424.

50. Singh, H.; Sindhu, J.; Khurana, J. M.; Sens. Actuators, B 2014, 192,536

51. Tripathy, S. K.; Woo, J. Y.; Han, C. S.; Sens. Actuators, B 2013, 181,114

52. Kaur, P.; Kaur, H.; Singh, K.; RSC Adv. 2013, 3, 64.

53. Apilux, A.; Dungchai, W.; Siangproh, W.; Praphairaksit, N.; Henry, C. S.; Chailapakul, O.; Anal. Chem. 2010, 82, 1727.

54. Mentele, M. M.; Cunningham, J.; Koehler, K.; Volckens, J.; Henry, C. S.; Anal. Chem. 2012, 84, 4474.

55. Rattanarat, P.; Dungchai, W.; Cate, D.; Volckens, J.; Chailapakul, O.; Henry, C. S.; Anal. Chem. 2014, 86, 3555.

56. Martinez, A. W.; Phillips, S. T.; Carrilho, E.; Thomas, S. W.; Sindi, H.; Whitesides, G. M.; Anal. Chem. 2008, 80, 3699.

Submitted: July 31, 2020 Published online: October 30, 2020 